\title{
Molecular Solar Thermal Power Generation
}

Zhihang Wang, ${ }^{1}$ Zhiyu Hu, ${ }^{2 *}$ Erzhen Mu, ${ }^{3}$ Zhao-Yang Zhang, ${ }^{4}$ Martyn Jevric, ${ }^{1}$ Yang Liu, ${ }^{2}$

Jessica Orrego-Hernández, ${ }^{1}$ Zhenhua Wu, ${ }^{2}$ Xuecheng Fu, ${ }^{5}$ Fengdan Wang, ${ }^{5} \mathrm{Tao} \mathrm{Li},{ }^{4 *}$ and Kasper Moth-Poulsen ${ }^{1 *}$

1. Department of Chemistry and Chemical Engineering, Chalmers University of Technology, 41296 Gothenburg, Sweden. E-mail: kasper.moth-poulsen@chalmers.se

2. National Key Laboratory of Science and Technology on Micro-Nano Fabrication, Shanghai Jiao Tong University (SJTU), Shanghai 200240, China. E-mail: zhiyuhu@ sjtu.edu.cn

3. School of Materials Science and Engineering, Henan Polytechnic University, Henan, 454003, China.

4. Shanghai Key Laboratory of Electrical Insulation and Thermal Aging, School of Chemistry and Chemical Engineering, Shanghai Jiao Tong University, Shanghai, 200240, China.

5. Center for Advanced Electronic, Materials and Devices (AEMD) of Shanghai Jiao Tong University, Shanghai, 200240, China. 


\section{Introduction}

With an increasing global population, total worldwide energy use from all sectors is expected to reach 21 TWy by 2040, corresponding to an increase of $130 \%$ compared to $2019 .{ }^{1}$ Electricity, alone, is an essential commodity in modern society, and around 3 TW is currently used each year. To complicate matters, about $85 \%$ of this current power is derived from fossil fuels. ${ }^{2}$ Therefore, the development of cleaner technologies for generating electricity is becoming increasingly important to offset negative environmental impacts. Solar energy is the most abundant energy resource on Earth, and committing to maximize the utilization of solar power can potentially meet this intensive demand while reducing detrimental effects to the environment. ${ }^{3}$ In fact, the total solar power that reaches Earth during a year is estimated to be $2.3 \times 10^{4} \mathrm{TWy}$, which equates to only seven hours of sunlight needed to address current annual global energy requirements. ${ }^{4,5}$

Photovoltaics (PV) can directly transform solar energy into electrical power. ${ }^{6-11}$ At the end of 2018, the annual global solar PV power capacity reached around $508 \mathrm{GW} .{ }^{12}$ Natural variations in solar intensity with time and geographical location currently limit the utilization of $\mathbf{P V}$; obviously, solar cells do not produce power during the night. Solar thermal power plants with phase change molten salts can generate power for several hours after sunset; however, these plants require solar concentrators of very large dimensions. ${ }^{13,14}$ Hence, it is of our interest to explore alternatives and compact technologies that can derive and store energy from the sun and later provide an energy source for electrical power generation.

To achieve solar energy storage, we have set out to use a class of materials that can capture sunlight via reversible photochemical reactions, and later release the stored energy on-demand; these materials are operating in a closed cycle. Such materials incorporate the use of photochromic chemical compounds, and so form the basis of molecular solar thermal energy 
storage systems (MOST). ${ }^{15-18}$ Upon exposure to sunlight, a suitable MOST material can photoisomerize to a high-energy metastable photoisomer, which preferably, can be stored in this form for extended periods of time. Depending on the photoswitch used, the back conversion reaction releasing heat energy can be triggered through different processes, including thermal, ${ }^{19,20}$ catalytic, ${ }^{21,22}$ electrocatalytic, ${ }^{23,24}$ or photoinduced back conversion. ${ }^{25-27}$ Such heat produced can be delivered locally and on-demand, as opposed to almost any other known thermal storage technology.

While MOST in closed cycle devices can be used for efficient storage and release of energy in the form of heat, additional engineering is necessary to address the electrical power generation from this heat production. Thermoelectric generator (TEG) devices can create electrical power from heat sources, and it has been used in various applications. ${ }^{28}$ Recently, new technological advances that enable power production from smaller temperature gradients using innovative micromechanical design are emerging. ${ }^{29-34}$

In this work, MOST systems are, for the first time, combined with an integrated microelectromechanical thermoelectric generation device (MEMS-TEG) ${ }^{35-37}$ to demonstrate the cascading energy flow from solar harvesting and storage to heat energy release which is finally used to generate power (see Figure. 1). Two photoswitches with suitable properties, a norbornadiene derivative (NBD) investigated as a solution and a phase interconvertible arylazopyrazole derivative (AZO) measured as a neat film, were selected for their potential to produce electricity. We characterized and coupled each of these photoswitches individually with an ultrathin highly sensitive MEMS-TEG chip (20 x $20 \mathrm{~mm})$, demonstrating that MOST stored chemical energy could successfully generate electrical power, thus affirming that solar energy for electrical power generation can be independent of time and geographical restrictions. 


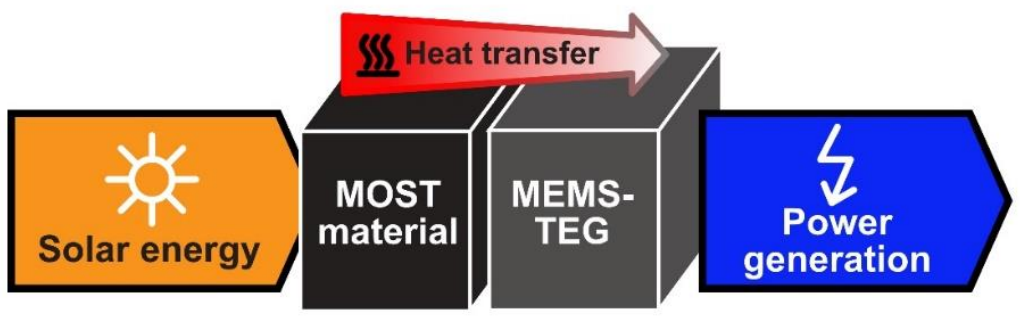

Figure 1. Schematic illustration of MOST to power generation concept. Solar energy can be collected by a MOST material. The stored energy can be released on-demand as latent heat, which is then converted to applicable power through a MEMS-TEG chip.

\section{Results and discussion}

\section{Solar energy storage properties}

MOST systems have been demonstrated formerly to function both in liquid and film forms, which can be tailored towards different applications..$^{21,38-45}$ Liquid form MOST provides the opportunity to transport stored energy, e.g., that energy storage and release could, in principle, be in two different locations. On the other hand, a MOST based film provides opportunities in terms of possible applications in smart windows and other device integrations. ${ }^{43,46}$ Herein, we selected and tested two systems, NBD in liquid form (toluene solution), and neat AZO in thin films that features suitable energy capture and storage functionality. The molecular structures of both photoswitch couples are shown in Figure. 2a. The photoconversion of NBD proceeds via a $[2+2 \pi]$ cycloaddition reaction to its corresponding photoisomer $\mathbf{Q C}$. Thus, the energy storage density $\Delta \mathrm{H}_{\text {storage }}$ was experimentally determined to be $93 \mathrm{~kJ} \cdot \mathrm{mol}^{-1}\left(367 \mathrm{~kJ} \cdot \mathrm{kg}^{-1}\right)$. Meanwhile, QC possesses a thermal back conversion half-life of one month at room temperature, demonstrating the possibility for long-term storage of QC in toluene. Spectroscopically, NBD exhibits an absorption feature around $340 \mathrm{~nm}$ with a maximum absorptivity of $\varepsilon_{\max @ 340 \mathrm{~nm}}=1.4 \times 10^{4} \mathrm{M}^{-1} \cdot \mathrm{cm}^{-1}$. In contrast, the absorption profile of $\mathbf{Q C}$ is virtually negligible above $300 \mathrm{~nm}$, consequently leaving a large transparent optical window 
between both forms (Figure. 2b). This significant spectral difference enables near quantitative photoconversion, even in concentrated solutions. In addition, the photoisomerization quantum yield was measured in toluene to be $68 \%$. With all the above suitable MOST properties considered, the solar energy storage efficiency of the system could reach upwards of $0.70 \% .{ }^{38}$ (see, Supplementary S2 for calculations)

a)
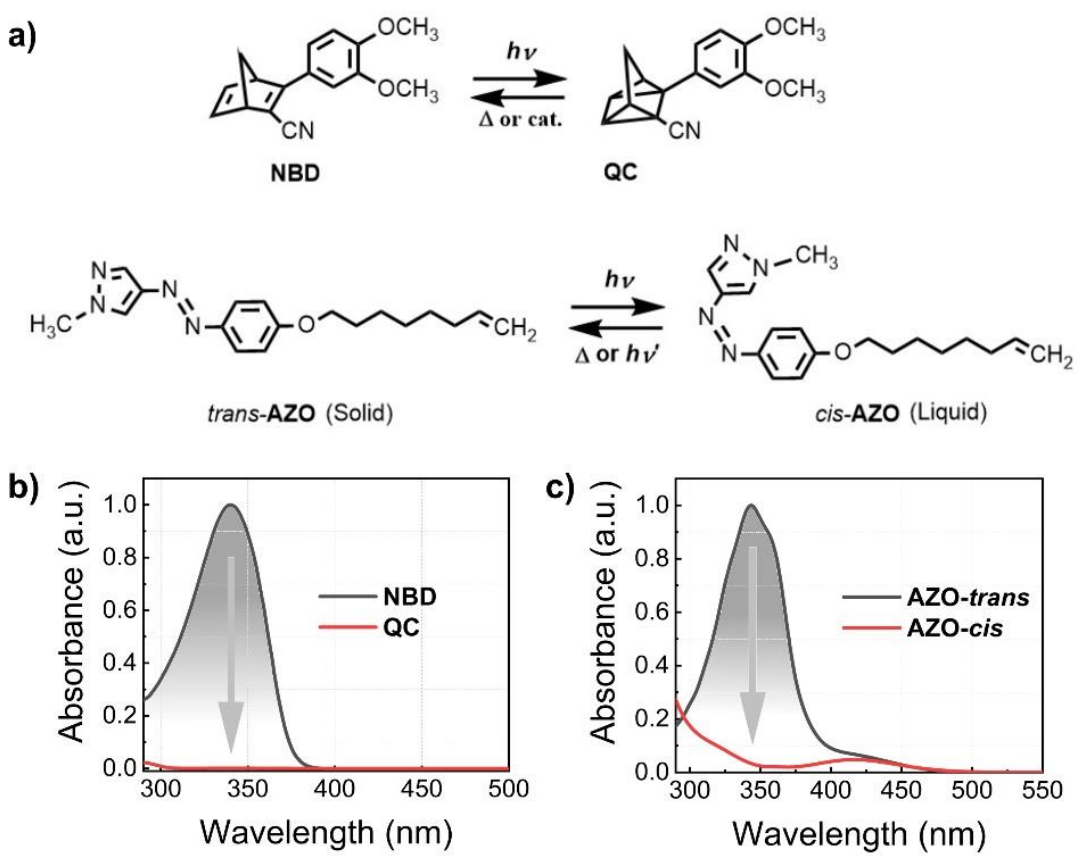

Figure 2. a) Molecular structures of NBD-QC couple (top) and trans/cis-AZO photoswitch couple (bottom). A thermal $(\Delta)$ or catalytic route (cat.) can facilitate the back-conversion of QC $\rightarrow$ NBD. The back-conversion of $c i s \rightarrow$ trans-AZO can be achieved by a thermal or lightinduced activation; b) Absorption profile of NBD before and after irradiation with $340 \mathrm{~nm}$ light (in toluene); c) Absorption profile of AZO photoswitch before and after irradiation with 365 $\mathrm{nm}$ light (in acetonitrile).

To take advantage of not just the exothermic process from photoisomerization reaction, but also from an additional phase change process (liquid $\rightarrow$ crystal), AZO photoswitch was investigated in its neat form. Previously, phase change materials (PCM) and TEG devices have been investigated for refrigeration applications. ${ }^{47}$ However, PCM can only release the stored 
latent heat, and the heat release is greatly dependent on the threshold temperature for the reverse phase change to occur. Currently, azo-based compounds have been chemically designed with PCM properties to improve the energy storage density. ${ }^{46,48-51}$ In case of cis-AZO, the stored energy can be easily released by irradiation with a $532 \mathrm{~nm}$ light source even with a low absorptivity. ${ }^{52}$ As shown in Figure. 2c, the absorption maximum of the trans-isomer is located at $344 \mathrm{~nm}$ with an absorptivity of $\varepsilon_{\max @ 340 \mathrm{~nm}}=2.9 \times 10^{4} \mathrm{M}^{-1} \cdot \mathrm{cm}^{-1}$, which is twice the extinction coefficient as the maxima determined for NBD, in addition to an $\lambda_{\text {onset }}=484 \mathrm{~nm}$. Unfortunately, AZO has a quantum yield of only $41 \%$; however, such value is still considered high for azobased photoswitches. The photoisomerization energy density $\Delta \mathrm{H}_{\text {isom }}$ was measured as 52 $\mathrm{kJ} \cdot \mathrm{mol}^{-1}\left(168 \mathrm{~kJ} \cdot \mathrm{kg}^{-1}\right)$. In addition to heat release from the chemical reaction, the crystal-toliquid transition $\left(\Delta \mathrm{H}_{\text {phase_change }}\right)$ can provide an additional $50 \mathrm{~kJ} \cdot \mathrm{mol}^{-1}\left(161 \mathrm{~kJ} \cdot \mathrm{kg}^{-1}\right)$ of thermal energy. As a result, the solar energy storage efficiency for AZO was previously estimated to be $1.2 \%$, much higher than previously measured azobenzene photoswitches. ${ }^{40}$ Moreover, cisAZO is remarkably stable at room temperature, with a thermal half-life of three months at $25{ }^{\circ} \mathrm{C}$. Thus, the advantage of using such a photoswitch would be from a neat film to take advantage of energy storage from two different sources of energy notably thermal ambient energy and light. ${ }^{46,52}$

Photoconversion in device under various exposure times and complete interconversion through multiple cycles are important tests for the viability of any given photoswitch in a MOST system. These experimental factors have previously been reported for AZO. ${ }^{46,52}$ Therefore, additional experiments were necessary for NBD to determine the compatibility of this photoswitch for the sake of this study. A custom made $400 \mathrm{~mm}^{2}$ microfluidic reactor was used for this photoconversion experiment. (See supplementary S3 for details) A solution of 0.1 M NBD (25 $\left.\mathrm{g} \cdot \mathrm{L}^{-1}\right)$ in toluene- $d_{8}$ was pumped through the microfluidic reactor with residence times that varied from $34 \mathrm{~s}$ to $343 \mathrm{~s}$. The degree of photoconversion could be conveniently monitored 
immediately afterwards by ${ }^{1} \mathrm{H}$ NMR spectroscopy. For an ideal MOST system, where the absorption of the photoisomer, in this case, $\mathbf{Q C}$, does not compete with the absorption of the parent NBD, the energy storage efficiency, $\eta_{\text {MOST, }}$, should remain approximately unchanged prior to full conversion. ${ }^{40,45,53}$ Here, We observed a decrease in solar energy storage efficiency from $\approx 0.5 \%$ at short residence times to $0.25 \%$ at full conversion. While not ideal, it is normal to observe a lowering of efficiency progressively during the conversion process. To date, in this context, this is the best system compared to our previous flow conversion results (see Figure $3 a) .{ }^{21}$ (See supplementary S4 for details)

Typically, for cyclability testing, solution based photoswitches are irradiated at time intervals at elevated temperatures. ${ }^{21,45}$ However, this method seemed impractical as $\mathbf{Q C}$, exhibits a long half-life ( $\mathrm{t}_{1 / 2} \approx 29$ days) in toluene. By taking this into consideration, an alternate protocol was employed which hastened the time frame for each successive cycle. Previously, It has been found that cobalt (II) phthalocyanine physisorbed on activated carbon $(\mathbf{C o P c} @ \mathbf{C})$, can rapidly facilitate the back-reaction of a very similar quadricyclane structure. ${ }^{21}$ This new setup involved converting and back-converting continuously a NBD solution ( $0.5 \mathrm{mM}$ in toluene) through the microfluidic reactor and the copper catalytic reactor in a closed cycle. Much to our delight, after 54 charge and discharge cycles on NBD, no obvious drop in performance was observed. (See figure 3b and 3c, supplementary S5 for details) It should be noted that, with such a setup, the total experimental time could be drastically reduced to only 61 hours.
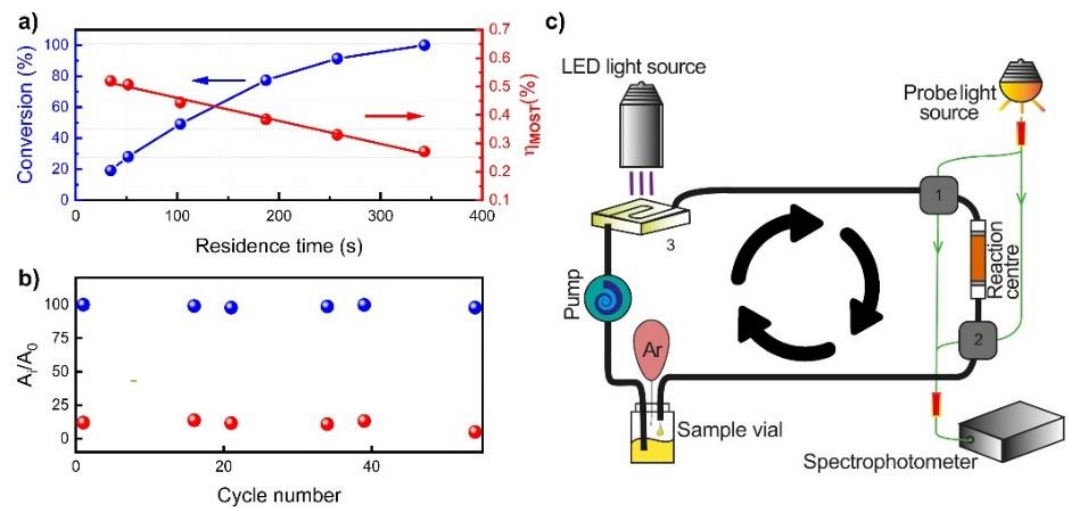
Figure 3. a) Conversion percentage (in blue) and calculated energy storage efficiency (in red) of $0.1 \mathrm{M}$ NBD in toluene as a function of residence time in the device. The solar simulator was calibrated to AM 1.5 solar irradiance; b) Normalized absorbance before irradiation with 340 nm LED light and after catalytic reactor. It has been observed that after 54 cycles, no degradation was observed; Blue dots show the normalized absorbance at $340 \mathrm{~nm}$, red dots show the normalized absorbance after irradiation. c) Cycling test setup for NBD. Box 1 and 2 represent the flow UV-Vis spectrometer before and after a catalytic reaction centre. Box 3 refers to the microfluidic chip. 3 mg of $\mathbf{C o P c} @ \mathbf{C}$ was loaded in the plastic reaction centre. Around $4 \mathrm{~mL}$ of $0.5 \mathrm{mM}$ NBD in toluene was prepared and passed through the whole setup with a speed of $50 \mu \mathrm{L} \cdot \mathrm{min}^{-1}$. The conversion process has proceeded with irradiation from a 340 nm LED lamp.

\section{Stored energy release for NBD and AZO}

Once solar energy is stored as $\mathbf{Q C}$ and cis-AZO, one should be able to release the chemical energy from these metastable compounds as heat. However, it was prudent to perform simulations to determine theoretically how much energy could actually be extracted from these charged materials. To achieve this, a simulation of potential temperature increases based on molecular parameters was performed. In the case of NBD, the maximum temperature gradient had a dependence on the saturation point of $\mathbf{Q C}$ in toluene. According to these calculations, the maximum temperature gradient under adiabatic conditions from the charged $\mathbf{Q C}$ solution was estimated to be $40^{\circ} \mathrm{C}$, based on saturated concentration of NBD in toluene. $(0.78 \mathrm{M}$, see supplementary S6 for details)

We designed a fixed bed catalytic heat release device consisting of a copper tube flanked on two sides with copper plates to maximize heat transfer for later coupling with the MEMS-TEG device. (See supplementary S7 for details) By taking advantage of the mobile nature of the QC 
solution, a heterogenous CoPc@ $\mathbf{C}$ catalyst ${ }^{21}$ was loaded inside the copper tube, and a thermally conductive pad was used to provide a homogeneous thermal distribution through the tube to all areas of the device. A saturated NBD solution was initially photoconverted to $\mathbf{Q C}$, and then pumped through the copper reactor with a flow speed of $5 \mathrm{~mL} \cdot \mathrm{h}^{-1}$. This speed leads to complete back-conversion from $\mathbf{Q C}$ to $\mathbf{N B D}$ and a maximum surface temperature of $37^{\circ} \mathrm{C}\left(\approx 13^{\circ} \mathrm{C}\right.$ temperature gradient), determined by a thermal camera focusing on the top of the device.

Concerning trans/cis-AZO photoswitch couple, the charged cis isomer releases $168 \mathrm{~kJ} \cdot \mathrm{kg}^{-1}$ equating to simulated heat increase of $84^{\circ} \mathrm{C}$. From here, an additional $161 \mathrm{~kJ}^{\mathrm{kg}} \mathrm{kg}^{-1}$ can be extracted at the crystalisation point of the trans-AZO (melting point $83{ }^{\circ} \mathrm{C}$ ) from the phase change event. Thus, cis-AZO theoretically shows a larger potential thermal gradient than the QC solution. In this case, the experimental measurement for the heat release involved the placement of a droplet of liquid cis-AZO $(\approx 8 \mathrm{mg})$ under ambient conditions onto a glass substrate $(1 \mathrm{~cm} \times 0.7 \mathrm{~cm})$. A $532 \mathrm{~nm}$ laser was used to irradiate the sample and trigger the heat release in conjunction with a thermal camera. Consequently, a full back-conversion was triggered, affording a maximum surface temperature of $52^{\circ} \mathrm{C}$, corresponding to a $17^{\circ} \mathrm{C}$ temperature gradient after the heat contribution from the laser had been accounted for. The large temperature gradient difference between theoretical and experimental values is likely because of the strong heat dissipation from this thin film under ambient conditions (Figure 4b, see supplementary S8 for details)

Accordingly, both solution-based NBD and neat AZO photoswitches can successfully generate heat, we now turned our attention towards utilising this heat energy and converting it to electrical power by coupling these two MOST formats with a MEMS-TEG device. 

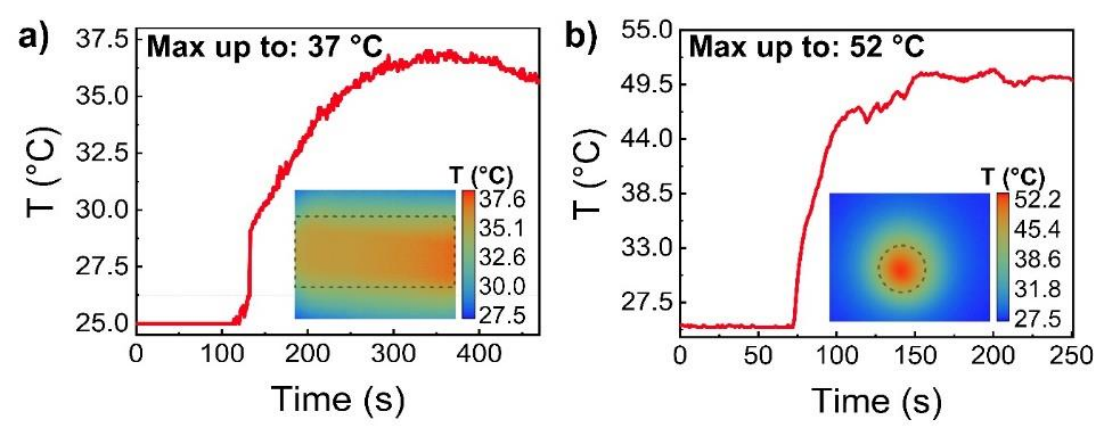

Figure 4. a) Recorded temperature increment of QC heat release over time; Inserted picture shows the thermal image from the heat releasing copper device. The area indicated by the dashed line represents the device position. A maximum absolute temperature of up to $37^{\circ} \mathrm{C}$ was recorded (temperature gradient of $13{ }^{\circ} \mathrm{C}$ ); b) Recorded temperature increment of AZO system over time; Inserted picture: thermal image from the heat releasing cis-AZO sample. The dashed line represents the position of the compound. A maximum absolute temperature increase of $52{ }^{\circ} \mathrm{C}$ was recorded (temperature gradient of $17^{\circ} \mathrm{C}$ after the heat generated from the laser is subtracted.);

\section{Power generation from NBD and AZO}

For the coupled power generation, we used one of the most efficient heat to power converters available, an ultrathin $800 \mathrm{~nm}$ N-type Bi2Te3/(Au), P-type Sb2Te3 multi-layered chip. The unit structure is designed in $\prod$ shape, with a resistance of $0.3 \Omega$ and a single $\mathrm{P} / \mathrm{N}$ surface area of $200 \mu \mathrm{m} \times 200 \mu \mathrm{m}$. (see Figure 5a and see supplementary S9 for details). In total, 572 units were connected in series, where the height of each thermoelectric column does not exceed 1 $\mu \mathrm{m}$, and the thickness of the gold electrode is about $300 \mathrm{~nm}$. Most importantly, the thickness of the working part of the chip does not exceed $2 \mu \mathrm{m}$. Thus, its ultrathin structure can respond effectively to temperature variations as little as $1 \times 10^{-4} \mathrm{~K}^{35}$ 

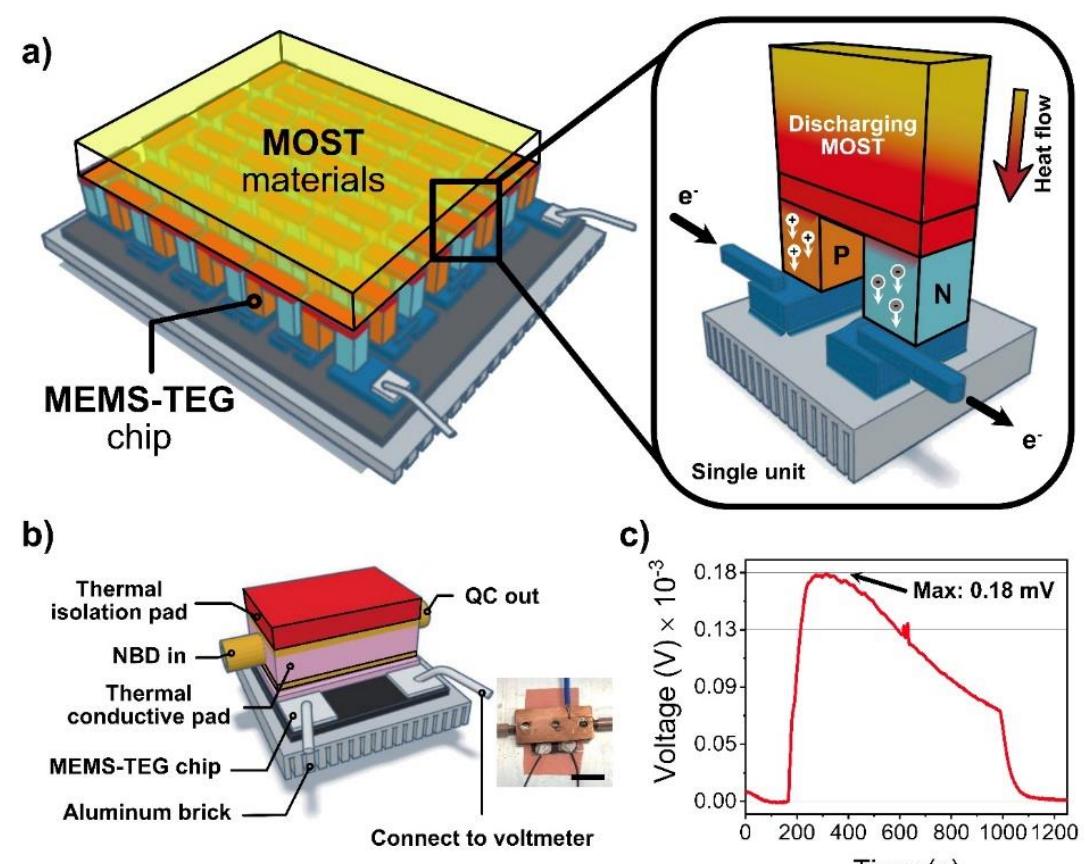

c)
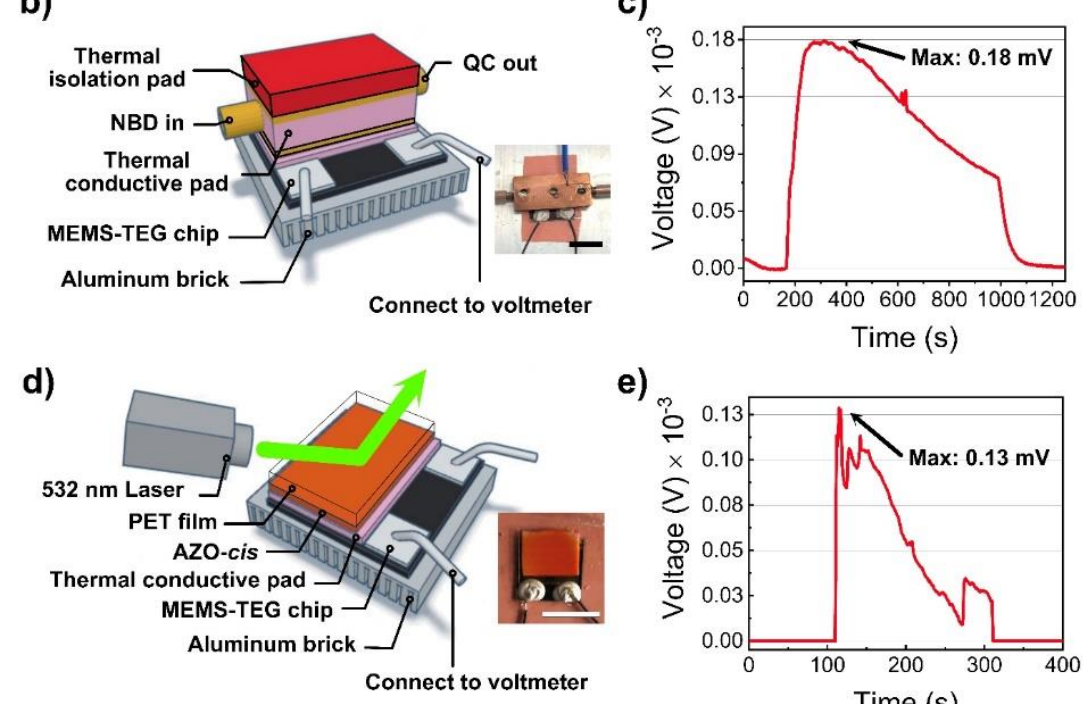

e)

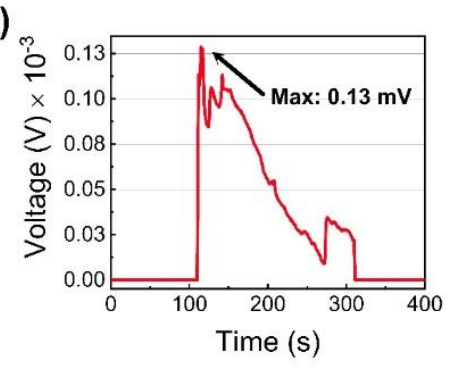

Figure 5. a) Schematic concept of MOST to power generation. The heat from the discharging MOST material can create heat flow to drive a MEMS-TEG chip for power generation; b) NBD solar energy storage for power generation experimental setup. The copper catalytic reactor was placed on top of the MEMS-TEG chip with a thermally conductive pad in between. The whole device was later fixed on top of an aluminum brick with and fully covered with a thermal insulation polymer to diminish the heat dissipation into the surrounding environment; The inset picture shows the actual device photo. The scale bar corresponds to $1 \mathrm{~cm}$; c) Heat release monitoring by thermocouple and voltage generated from MEMS-TEG chip over time. A maximum voltage up to $0.18 \mathrm{mV}$ was successfully observed; d) Schematic experimental setup of AZO solar energy for power generation. cis-AZO sample was drop cast on the surface of the thermally conductive pad, then positioned on the top of the MEMS-TEG chip. A PET 
film set on top of the AZO sample ensured a homogeneous distribution of the MOST material. The back-conversion is triggered by a laser source of $532 \mathrm{~nm}\left(110 \mathrm{~mW} \cdot \mathrm{cm}^{-2}\right.$, the beam diameter of $1.3 \mathrm{~cm}$. The laser source was able to illuminate all areas of AZO sample continuously); The inset picture shows the actual device photo. Scale bar corresponds to $1 \mathrm{~cm}$; e) Net voltage generated from MEMS-TEG chip over time. A maximum voltage up to $0.13 \mathrm{mV}$ was successfully observed.

Based on the physical properties of NBD and AZO, two heat-to-power generation device concepts were put forth. For the NBD system, a saturated solution of $\mathbf{Q C}$ in toluene was prepared in Gothenburg, Sweden, using a photochemical flow reactor (See supplementary S10 for details) and shipped to Shanghai, China. For this experiment, 5 mg of $\mathbf{C o P c} @ \mathbf{C}$ was loaded inside the catalytic reactor (inside the central copper tube), where a thermally conductive pad was used to fill the gap between copper plates in the device (see Figure $5 b$ ). The reactor was placed above the MEMS-TEG chip, and the whole setup was then placed on top of an aluminum brick heat sink, which ensured a stable ambient temperature and served as the cold side of the device. Importantly, a thermally insulated plastic foam was used to cover the hot side of the system to ensure that the heat generated is reflected instead of losing to the environment. As a result, with less than $1 \mathrm{~mL}$ of a $0.78 \mathrm{M}$ solution and a flow speed of $5 \mathrm{~mL} \cdot \mathrm{h}^{-}$ ${ }^{1}$, a measured bias voltage of up to $0.18 \mathrm{mV}$ was recorded. According to MEMS-TEG chip characterization, this voltage can generate an output power of $\approx 0.05 \mathrm{nW}^{35}$ (surface output power of $1.2 \mathrm{~mW} \cdot \mathrm{m}^{-2}$ ). As the operating time of the experiment is around $800 \mathrm{~s}$, the average heat to electric power conversion efficiency was calculated to be $0.56 \times 10^{-7} \%$ (see Figure $5 \mathrm{c}$ ).

In the case of AZO, a smaller amount of material was employed. In this instance, $7 \mathrm{mg}$ of cisAZO, generated from a $365 \mathrm{~nm}$ LED light source, was loaded onto the thermally conductive pad. A PET film was gently pressed on top of the material to allow the material to fully cover the surface of the MEMS-TEG chip evenly. Laser irradiation at $532 \mathrm{~nm}$ triggered the back 
conversion (see Figure 5d), leading to a bias output voltage up to $0.13 \mathrm{mV}$. Such value corresponds to a maximum output power of $0.02 \mathrm{nW}$ (surface power density of $0.6 \mathrm{~mW} \cdot \mathrm{m}^{-2}$ ). With a heat release time of around $200 \mathrm{~s}$, the average heat to electric power conversion efficiency in this case is calculated to be $1.7 \times 10^{-7} \%$. (See supplementary S11 for details) Interestingly, various peaks were observed when the voltage approached the maximum. This was likely due to the complex heat release behaviour that involved both photo-isomerization and phase transitions. (see Figure 5e) It can also be observed from the figures that less power is generated from AZO than from NBD, although the former reached a higher surface temperature. Not surprisingly, this is because the amount of heat that is released from these two systems is markedly different, as $1 \mathrm{~mL}$ of $0.78 \mathrm{M} \mathrm{QC}$ could ideally produce $72.5 \mathrm{~J}$, while $7 \mathrm{mg}$ coated AZO was only capable of producing $2.3 \mathrm{~J}$ of energy.

Hence, to the best of our knowledge, both results show for the first time, a proof-of-principle of solution based MOST and PCM-MOST systems that have been used to generate electric power. Future developments should focus on red shifting the absorption band (capturing more sun light) and increasing the temperature gradient produced in the back reaction (improving energy density). In addition, as the proof-of-concept, the thermoelectric conversion efficiencies for both demonstrations need to be further improved with mechanical design. A future device construction should include a better thermal management system to avoid heat dissipation from MOST to the surrounding environment, thereby increasing the amount of heat energy converted to electrical output power. For instance, in an ideal case, the thermoelectric efficiency is estimated to be up to $10 \%$ (See Supplementary S12 for details). If we produce a highly soluble photoswitch of ca. $1.5 \mathrm{M}$, accompanied by a heat release of $100 \mathrm{~kJ} \mathrm{~mol}^{-1}$ with a $5 \mathrm{~mL} \cdot \mathrm{h}^{-1}$ flow speed, and assuming that an absolute temperature of $100{ }^{\circ} \mathrm{C}$ could be achieved, which is close to what has recently been demonstrated. ${ }^{21}$ The system should be able to produce 
an output power of $40 \mathrm{~mW}\left(500 \mathrm{~kW} \cdot \mathrm{m}^{-2}\right)$, enough to power a low power supplied internet of things (IoT) device. ${ }^{54}$

\section{Conclusions}

In this work, we have explored the use of two molecular photoswitches in a different physical form (liquid-based NBD and neat AZO film), for the purpose coupling MOST with thermoelectric device. The liquid-based NBD exhibits a solar energy storage efficiency of $\approx$ $0.5 \%$ with only $0.5 \mathrm{mM}$ in toluene, more competitive with photosynthesis $(0.1 \%-0.3 \%) .{ }^{55} \mathrm{In}$ addition, the compound was tested through 54 charge and discharge cycles in a continuously operating energy storage and catalysed release cycle, showing no sign of degradation. Alternatively, The PCM-MOST hybrid neat AZO film captures and releases energy in photochemical solid-liquid transitions, which allows the MOST to harness energy both from sunlight and from the ambient environment, meaning that upgraded heat can be produced ondemand.

To demonstrate MOST to power generation, an ultrathin, highly sensitive MEMS-TEG device was used to capture the heat released arising from either scenario. For the first time, electricity was produced in this setup, with output power up to $0.05 \mathrm{nW}$ (output power per unit surface up to $1.2 \mathrm{~mW} \cdot \mathrm{m}^{-2}$ ). We note that this is a very compact and local solar energy storage system that operates through an entirely different mechanism than traditional photovoltaic - battery storage combinations. Furthermore, these types of system have the possibility of being charged and discharged across different geographic locations (Sweden to China in this work), ultimately showing the potential of storing and using solar energy for power generation. While the efficiencies of the systems need to be improved, we envision such systems used in future local power generation applications.

\section{Author contributions}


Z.W. performed all the material characterizations, conversion tests, cycling tests, heat release experiments, and power generation demonstrations. E.M. and Z.Y.Z. performed the heat release experiments and power generation experiments. Y. L., X. F. and F. W. performed MEMS-TEG chip fabrication. Z. Wu. carried out the thermoelectric efficiency simulation. J.O.H performed the sample preparation with an automated flow system. M.J. and Z.Y.Z synthesized the used compounds. Z. W., Z. H., T.L., and K.M.P. designed the experiments. All authors contributed to writing the manuscript.

\section{Conflicts of interest}

There are no conflicts to declare.

\section{Acknowledgements}

This work was supported by the K. \& A. Wallenberg foundation and the Swedish Foundation for Strategic Research. The MEMS-TEG chip fabrication and experiment were supported by National Natural Science Foundation of China (Grant No: 51776126) and Yunnan Hu Zhiyu Expert Workstation [(2014) 5]. The authors would like to thank the Center for Advanced Electronic Materials and Devices (AEMD) and Instrumental Analysis Center of Shanghai Jiao Tong University (SJTU), and the startup fund of Shanghai Jiao Tong University. We thank Dr.

Sarah Lerch and Prof. Ben Greatrex for reading and commenting on this manuscript.

\section{References}

1. plc, B. (2019). BP Statistical Review of World Energy, 68 edn.

2. Gautam, P., Kumar, S., and Lokhandwala, S. (2019). Chapter 11 - Energy-Aware Intelligence in Megacities. In Current Developments in Biotechnology and Bioengineering, S. Kumar, R. Kumar, and A. Pandey, eds. (Elsevier), pp. 211-238.

3. Lewis, N.S., and Nocera, D.G. (2006). Powering the planet: Chemical challenges in solar energy utilization. Proceedings of the National Academy of Sciences 103, $15729-15735$. 
4. Perez, R., and Perez, M. (2009). IEA-SHCP-Newsletter 50.

5. Perez, R., and Perez, M. (2015). IEA-SHCP-Newsletter 62.

6. Parida, B., Iniyan, S., and Goic, R. (2011). A review of solar photovoltaic technologies. Renew. Sustain. Energy Rev 15, 1625-1636.

7. Jordehi, A.R. (2016). Parameter estimation of solar photovoltaic (PV) cells: A review. Renew. Sustain. Energy Rev 61, 354-371.

8. Hosenuzzaman, M., Rahim, N.A., Selvaraj, J., Hasanuzzaman, M., Malek, A.B.M.A., and Nahar, A. (2015). Global prospects, progress, policies, and environmental impact of solar photovoltaic power generation. Renew. Sustain. Energy Rev 41, 284-297.

9. Sobri, S., Koohi-Kamali, S., and Rahim, N.A. (2018). Solar photovoltaic generation forecasting methods: A review. Energy Convers. Manage. 156, 459-497.

10. Sahu, A., Yadav, N., and Sudhakar, K. (2016). Floating photovoltaic power plant: A review. Renew. Sustain. Energy Rev 66, 815-824.

11. An, Q., Zhang, F., Zhang, J., Tang, W., Deng, Z., and Hu, B. (2016). Versatile ternary organic solar cells: a critical review. Energy Environ. Sci. 9, 281-322.

12. Global Market Outlook For Solar Power /2019 - 2023 (SolarPower Europe).

13. Herrmann, U., Kelly, B., and Price, H. (2004). Two-tank molten salt storage for parabolic trough solar power plants. Energy 29, 883-893.

14. Du, K., Calautit, J., Wang, Z., Wu, Y., and Liu, H. (2018). A review of the applications of phase change materials in cooling, heating and power generation in different temperature ranges. Appl. Energy 220, 242-273.

15. Yoshida, Z.-i. (1985). New molecular energy storage systems. J. Photochem. 29, 27-40.

16. Moth-Poulsen, K., Ćoso, D., Börjesson, K., Vinokurov, N., Meier, S.K., Majumdar, A., Vollhardt, K.P.C., and Segalman, R.A. (2012). Molecular solar thermal (MOST) energy storage and release system. Energy Environ. Sci. 5, 8534-8537. 
17. Kolpak, A.M., and Grossman, J.C. (2011). Azobenzene-Functionalized Carbon Nanotubes As High-Energy Density Solar Thermal Fuels. Nano Lett. 11, 3156-3162.

18. Kucharski, T.J., Ferralis, N., Kolpak, A.M., Zheng, J.O., Nocera, D.G., and Grossman, J.C. (2014). Templated assembly of photoswitches significantly increases the energy-storage capacity of solar thermal fuels. Nat. Chem. 6, 441-447.

19. Bren, V.A., Dubonosov, A.D., Minkin, V.I., and Chernoivanov, V.A. (1991). Norbornadiene-quadricyclane - an effective molecular system for the storage of solar energy. Russ. Chem. Rev. 60, 451-469.

20. Broman, S., Brand, S., Parker, C., Petersen, M., Tortzen, C., Kadziola, A., Kilså, K., and Nielsen, M. (2011). Optimized synthesis and detailed NMR spectroscopic characterization of the 1,8a-dihydroazulene-1,1-dicarbonitrile photoswitch. Arkivoc 2011, 51-67.

21. Wang, Z., Roffey, A., Losantos, R., Lennartson, A., Jevric, M., Petersen, A.U., Quant, M., Dreos, A., Wen, X., Sampedro, D., et al. (2019). Macroscopic heat release in a molecular solar thermal energy storage system. Energy Environ. Sci. 12, 187-193.

22. Cacciarini, M., Vlasceanu, A., Jevric, M., and Nielsen, M. (2017). An effective trigger for energy release of vinylheptafulvene-based solar heat batteries. Chem. Commun. 53.

23. Brummel, O., Waidhas, F., Bauer, U., Wu, Y., Bochmann, S., Steinrück, H.-P., Papp, C., Bachmann, J., and Libuda, J. (2017). Photochemical Energy Storage and Electrochemically Triggered Energy Release in the Norbornadiene-Quadricyclane System: UV Photochemistry and IR Spectroelectrochemistry in a Combined Experiment. J. Phys. Chem. Lett. 8, 2819-2825.

24. Waidhas, F., Jevric, M., Bosch, M., Yang, T., Franz, E., Liu, Z., Bachmann, J., Moth-Poulsen, K., Brummel, O., and Libuda, J. (2020). Electrochemically controlled energy release from a norbornadiene-based solar thermal fuel: increasing the reversibility to $99.8 \%$ using HOPG as the electrode material. J. Mater. Chem. A 8 , $15658-15664$.

25. Fu, L., Yang, J., Dong, L., Yu, H., Yan, Q., Zhao, F., Zhai, F., Xu, Y., Dang, Y., Hu, W., et al. (2019). Solar Thermal Storage and Room-Temperature Fast Release Using a Uniform Flexible Azobenzene-Grafted Polynorborene Film Enhanced by Stretching. Macromolecules 52, 4222-4231.

26. Hu, J., Huang, S., Yu, M., and Yu, H. (2019). Flexible Solar Thermal Fuel Devices: Composites of Fabric and a Photoliquefiable Azobenzene Derivative. Adv. Energy Mater. 9, 1901363. 
27. Yan, Q., Zhang, Y., Dang, Y., Feng, Y., and Feng, W. (2020). Solid-state highpower photo heat output of 4-((3,5-dimethoxyaniline)-diazenyl)-2-

imidazole/graphene film for thermally controllable dual data encoding/reading. Energy Storage Mater. 24, 662-669.

28. Jaziri, N., Boughamoura, A., Müller, J., Mezghani, B., Tounsi, F., and Ismail, M. (2019). A comprehensive review of Thermoelectric Generators: Technologies and common applications. Energy Reports.

29. See, K.C., Feser, J.P., Chen, C.E., Majumdar, A., Urban, J.J., and Segalman, R.A. (2010). Water-Processable Polymer-Nanocrystal Hybrids for Thermoelectrics. Nano Lett. 10, 4664-4667.

30. Bubnova, O., Khan, Z.U., Malti, A., Braun, S., Fahlman, M., Berggren, M., and Crispin, X. (2011). Optimization of the thermoelectric figure of merit in the conducting polymer poly(3,4-ethylenedioxythiophene). Nat. Mater. 10, 429-433.

31. Kroon, R., Mengistie, D.A., Kiefer, D., Hynynen, J., Ryan, J.D., Yu, L., and Müller, C. (2016). Thermoelectric plastics: from design to synthesis, processing and structure-property relationships. Chem. Soc. Rev. 45, 6147-6164.

32. Beretta, D., Neophytou, N., Hodges, J.M., Kanatzidis, M.G., Narducci, D., MartinGonzalez, M., Beekman, M., Balke, B., Cerretti, G., Tremel, W., et al. (2019). Thermoelectrics: From history, a window to the future. Materials Science and Engineering: R: Reports 138, 100501.

33. Bell, L.E. (2008). Cooling, Heating, Generating Power, and Recovering Waste Heat with Thermoelectric Systems. Science 321, 1457-1461.

34. He, R., Schierning, G., and Nielsch, K. (2018). Thermoelectric Devices: A Review of Devices, Architectures, and Contact Optimization. Adv. Mater. Technol. 3, 1700256.

35. Liu, Y., Mu, E., Wu, Z., Che, Z., Sun, F., Fu, X., Wang, F., Wang, X., and Hu, Z. (2020). Ultrathin MEMS thermoelectric generator with Bi2Te3/(Pt, Au) multilayers and Sb2Te3 legs. Nano Converg. 7, 8.

36. Mu, E., Wu, Z., Wu, Z., Chen, X., Liu, Y., Fu, X., and Hu, Z. (2019). A novel selfpowering ultrathin TEG device based on micro/nano emitter for radiative cooling. Nano Energy 55, 494-500. 
37. Mu, E., Yang, G., Fu, X., Wang, F., and Hu, Z. (2018). Fabrication and characterization of ultrathin thermoelectric device for energy conversion. Journal of Power Sources 394, 17-25.

38. Jevric, M., Petersen, A.U., Mansø, M., Kumar Singh, S., Wang, Z., Dreos, A., Sumby, C., Nielsen, M.B., Börjesson, K., Erhart, P., et al. (2018). NorbornadieneBased Photoswitches with Exceptional Combination of Solar Spectrum Match and Long-Term Energy Storage. Chem. Eur. J. 24, 12767-12772.

39. Dreos, A., Wang, Z., Udmark, J., Ström, A., Erhart, P., Börjesson, K., Nielsen, M.B., and Moth-Poulsen, K. (2018). Liquid Norbornadiene Photoswitches for Solar Energy Storage. Adv. Energy Mater. 8, 1703401.

40. Wang, Z., Losantos, R., Sampedro, D., Morikawa, M.-a., Börjesson, K., Kimizuka, N., and Moth-Poulsen, K. (2019). Demonstration of an azobenzene derivative based solar thermal energy storage system. J. Mater. Chem. A 7, 15042-15047.

41. Masutani, K., Morikawa, M.-a., and Kimizuka, N. (2014). A liquid azobenzene derivative as a solvent-free solar thermal fuel. Chem. Commun. 50, 15803-15806.

42. Quant, M., Lennartson, A., Dreos, A., Kuisma, M., Erhart, P., Börjesson, K., and Moth-Poulsen, K. (2016). Low Molecular Weight Norbornadiene Derivatives for Molecular Solar-Thermal Energy Storage. Chem. Eur. J. 22, 13265-13274.

43. Petersen, A.U., Hofmann, A.I., Fillols, M., Mansø, M., Jevric, M., Wang, Z., Sumby, C.J., Müller, C., and Moth-Poulsen, K. (2019). Solar Energy Storage by Molecular Norbornadiene-Quadricyclane Photoswitches: Polymer Film Devices. Adv. Sci. 6, 1900367.

44. Morikawa, M.-a., Yang, H., Ishiba, K., Masutani, K., Hui, J.K.-H., and Kimizuka, N. (2020). A Liquid Arylazopyrazole Derivative as Molecular Solar Thermal Fuel with Long-term Thermal Stability. Chem. Lett. 49, 736-740.

45. Wang, Z., Udmark, J., Börjesson, K., Rodrigues, R., Roffey, A., Abrahamsson, M., Nielsen, M.B., and Moth-Poulsen, K. (2017). Evaluating Dihydroazulene/Vinylheptafulvene Photoswitches for Solar Energy Storage Applications. ChemSusChem 10, 3049-3055.

46. Zhang, Z.-Y., He, Y., Wang, Z., Xu, J., Xie, M., Tao, P., Ji, D., Moth-Poulsen, K., and Li, T. (2020). Photochemical Phase Transitions Enable Coharvesting of Photon Energy and Ambient Heat for Energetic Molecular Solar Thermal Batteries That Upgrade Thermal Energy. J. Am. Chem. Soc. 142, 12256-12264. 
47. Riffat, S.B., Omer, S.A., and Ma, X. (2001). A novel thermoelectric refrigeration system employing heat pipes and a phase change material: an experimental investigation. Renew. Energy 23, 313-323.

48. Gerkman, M.A., Gibson, R.S.L., Calbo, J., Shi, Y., Fuchter, M.J., and Han, G.G.D. (2020). Arylazopyrazoles for Long-Term Thermal Energy Storage and OpticallyTriggered Heat Release below $0{ }^{\circ} \mathrm{C}$. J. Am. Chem. Soc. 142, 8688-8695.

49. Gerkman, M.A., and Han, G.G.D. (2020). Toward Controlled Thermal Energy Storage and Release in Organic Phase Change Materials. Joule.

50. Ishiba, K., Morikawa, M.-a., Chikara, C., Yamada, T., Iwase, K., Kawakita, M., and Kimizuka, N. (2015). Photoliquefiable Ionic Crystals: A Phase Crossover Approach for Photon Energy Storage Materials with Functional Multiplicity. Angew. Chem. Int. Ed. 54, 1532-1536.

51. Han, G.G.D., Li, H., and Grossman, J.C. (2017). Optically-controlled long-term storage and release of thermal energy in phase-change materials. Nat. Commun. 8 , 1446.

52. Zhang, Z.-Y., He, Y., Zhou, Y., Yu, C., Han, L., and Li, T. (2019). Pyrazolylazophenyl Ether-Based Photoswitches: Facile Synthesis, (Near-)Quantitative Photoconversion, Long Thermal Half-Life, Easy Functionalization, and Versatile Applications in Light-Responsive Systems. Chem. Eur. J. 25, 13402-13410.

53. Hansen, M.H., Olsen, S.T., Sylvester-Hvid, K.O., and Mikkelsen, K.V. (2019). Simulation framework for screening of molecular solar thermal systems in the context of a hybrid device. Chemical Physics 519, 92-100.

54. Lee, H.G., and Chang, N. (2015). Powering the IoT: Storage-less and converterless energy harvesting. Paper presented at: The 20th Asia and South Pacific Design Automation Conference.

55. Scharf, H.-D., Fleischhauer, J., Leismann, H., Ressler, I., Schleker, W.-g., and Weitz, R. (1979). Criteria for the Efficiency, Stability, and Capacity of Abiotic Photochemical Solar Energy Storage Systems. Angewandte Chemie International Edition in English 18, 652-662. 